\title{
Sustaining Water-Related Heritage Infrastructures as Part of An Integrated Water Resource Management Program
}

\author{
Radianta Triatmadja*, Djoko Legono, Budi Wignyosukarto, \\ Fatchan Nurrochmad, Sunjoto \\ Department of Civil and Environmental Engineering, Universitas Gadjah Mada, Yogyakarta, INDONESIA \\ Jalan Grafika No 2 Yogyakarta \\ *Corresponding authors: radianta@ugm.ac.id
}

SUBMITTED 15 November 2019 REVISED 21 February 2020 ACCEPTED 6 March 2020

\begin{abstract}
The history of the water resources development in the world is generally inspired by the physical, climate and socioenvironment conditions such as geographical, culture and civilization at the local level. For many years, humans have spent tremendous efforts and time improving the quality of life through adequate water utilization. This research, therefore, aims to analyze the ancient water-related infrastructures as cultural heritages in creating a functional and adequate design. Data were obtained from the Mataram Canal in Yogyakarta Province which was selected due to the success story and various benefits associated with the Indonesian history of water resources in Central Java provinces. Today, some places along the canal have become tourist destinations, and it is more popular in Yogyakarta due to its architectural history. However, the diversification of water utilization in fishery ponds along the canal and the shift in land utilization from rice field to housings, and government buildings may undermine the function of the canal. The factual condition associated with the periodic decrease in irrigation command does not make the Mataram Canal useless. Therefore, efforts to maintain its function through restoration, and revitalization, can enhance water supply for irrigation and other purposes such as fish ponds and, pollutant dilution. The Strength-Weakness-Opportunity-Threat (SWOT) method with some key performance indicators were adopted to access the necessity of the sustainability program of the Mataram Canal as the heritage infrastructure. Some key performance indicators related to Integrated Water Resources Management (IWRM) program in Indonesia were introduced and utilized to prioritize the necessary actions. The results showed that the SWOT analysis promotes various actions to support the IWRM-related program of Mataram Canal. Furthermore, the implementation of the promoted actions would contribute to the longer sustainability of the Mataram Canal.
\end{abstract}

KEYWORDS Heritage; Water-related; Infrastructures; Sustainable; SWOT Method.

(c) The Author(s) 2020. This article is distributed under a Creative Commons Attribution-ShareAlike 4.0 International license.

\section{INTRODUCTION}

Water is a natural resource with adequate quality and quantity in existence since ancient times. Its technological developments, and use in legislative and local wisdom, started a long time ago. The past culture of water has become a property value believed to improve the local economy (Vishwanath, 2010). Some historical structures related to water such as the welled basins in Hampi in Karnataka and Abaneri in Rajahtan showed that a high perimeter was utilized thousands of years ago. Figure 1 shows very large open wells (surrounded by beautiful granite rocks and other structures such as aqueducts, which carry water from the hills to the city. Dams of granite or brick masonry are few examples of sustainable water cultural heritage.

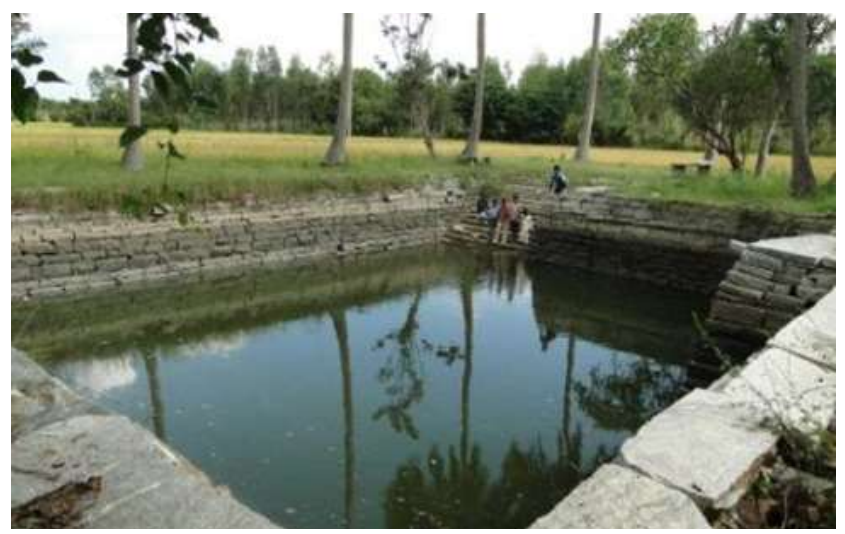

Figure 1 Open-well for domestic water fulfillment (Vishwanath, 2010) 
Water is a crucial resource that represents civilization (Rao, 2017). During the early days, people harvested, stored, and delivered water their homes for survival. Gradually they learned how to channel water to the cities. The Baoli city in India is an example of a highly civilized area where water is harvested. Originating from the Indian subcontinent, baolis are step-wells or ponds in which water is obtained by descending a flight of steps. They can be multi-stories with a bullock used to turn the wheel to raise well water to the first or second floor (see Figure 2).

There are three major benefits associated with maintaining the water infrastructure of the Baoli as follow (Rao, 2017):

a) Creating public awareness on the historic and architectural relevance of water infrastructures, to save the city from urban pressure, deterioration, and neglect.

b) Rejuvenating its precincts and creating safe spaces.

c) Reviving these water systems.

Information on the previous design data, is needed to have adequate understanding of the functional design which is often difficult. Some modalities include traditional images such as Tatsumi Channel in Japan which was destroyed by the shepherd in 1799 (Tamai, et al., 2018). Furthermore, the reasons for moving the intake siphon was determined after obtaining a traditional drawing submitted by the community to the autonomous government of Kanazawa in 2016. The Tatsumi Channel, as shown in Figure 3, was built in 1632 to bring water to the city of Kanazawa and in order to extinguish fires that often destroy many areas in the city castle.

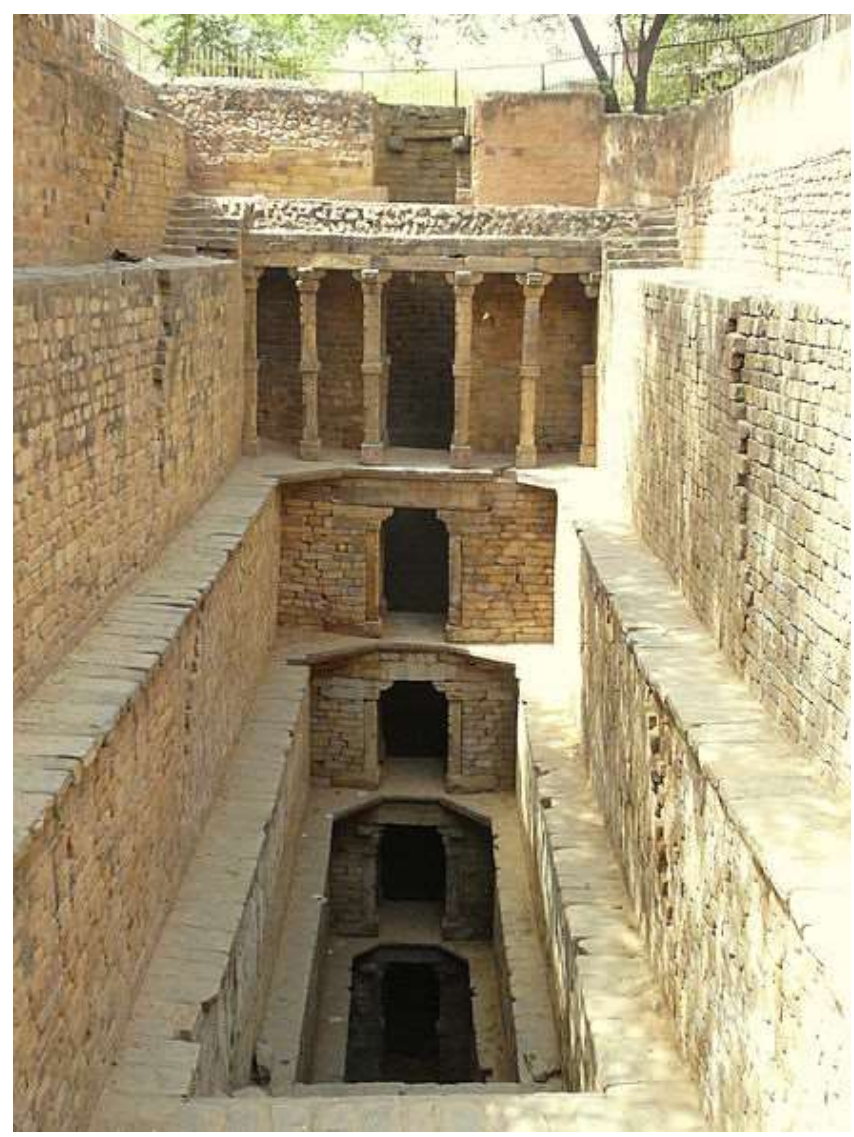

(a). Gandhak Ki Baoliof India in. dry condition (https://en.wikipedia.org/wiki/Baolis_of_Mehrauli)

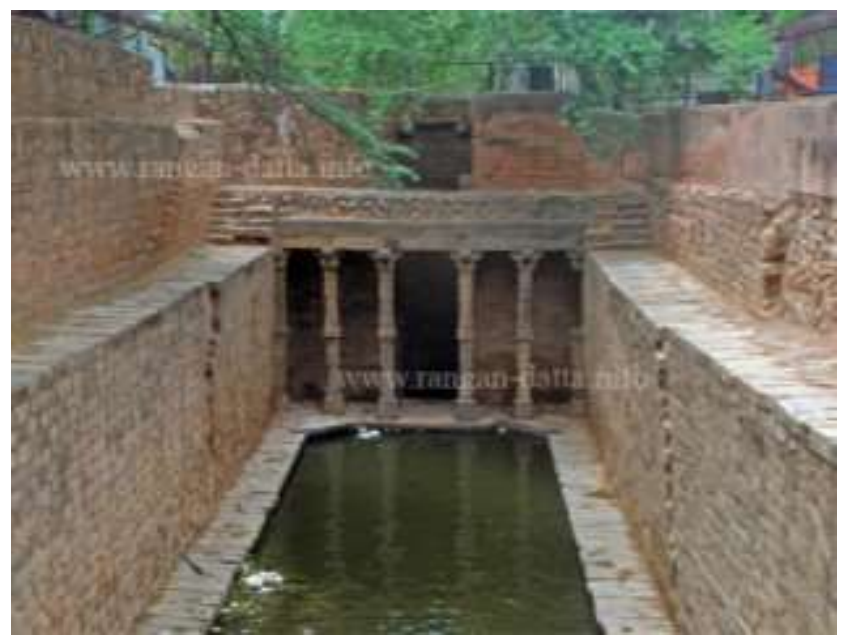

(b). Gandhak Ki Baoliof India in wet condition (https://rangandatta.wordpress.com/20170510/baolisstep-wells-of-delhi )

Figure 2. Gandhak Ki Baoliof India 


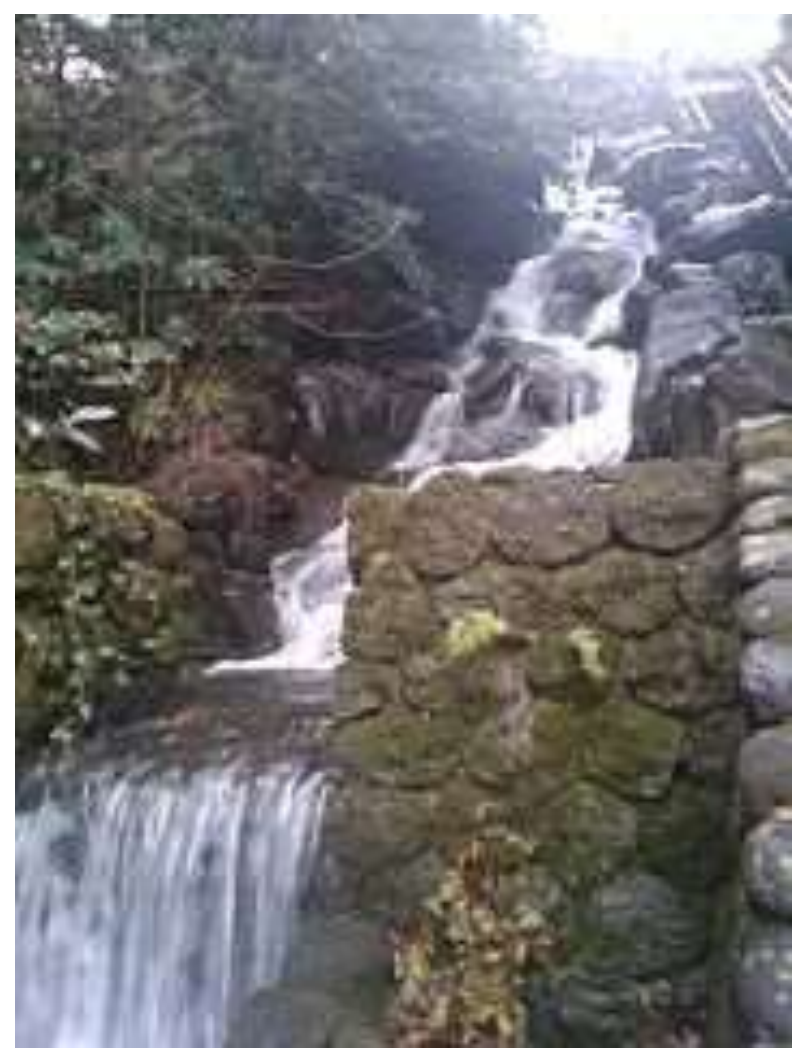

(a). Tatsumi Canal with drop structure

(https://commons.wikimedia.org/wiki/Category:Tatsumi _Canal\#/media/File:Tatsumi_canal_(Falls).jpg )

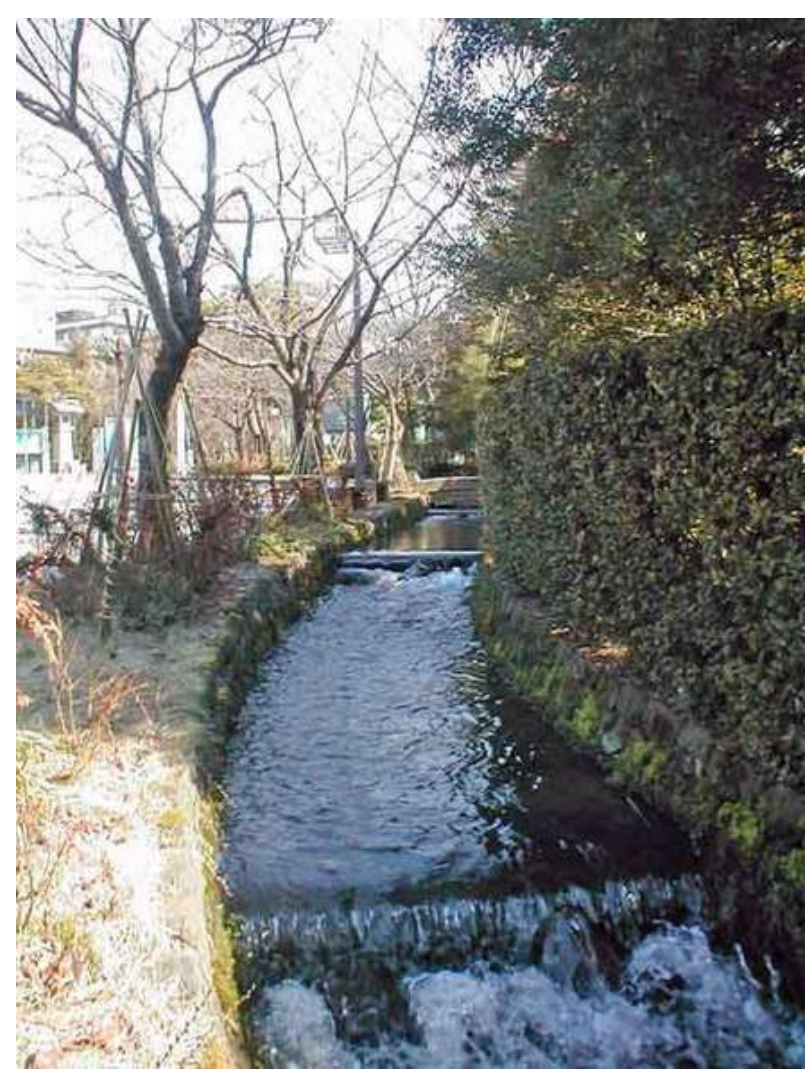

(b). Tatsumi Canal across the city

(https://en.wikipedia.org/wiki/Tatsumi_Canal)

Figure 3 Tatsumi Canal of Kanazawa Prefecture
The above three figures show that the necessity to sustain the water infrastructure heritage is a contributing factor to the various benefits in supporting its management program. This is followed by the valuation of the Mataram Canal as the water infrastructure heritage that needs to be sustained.

This canal runs from west to east splitting the Yogyakarta Province into two and connects the Progo River in the West to the Opak in the East as shown in Figure 4. It was originally called Yashiro and runs down to the east at a total length of 30.8 km. In 1944, Sri Sultan Hamengkubuwono IX started the construction of Mataram Canal in order to save the Yogyakarta people from Romusha under Japanese occupation. It consists of JSIM, Karangtalun ( $3 \mathrm{~km}$ ) and Van der Wijck (17 $\mathrm{km}$ ) canals created to irrigate various agricultural land areas, especially in the northern part of Yogyakarta, for people to harvest throughout the year. Before the construction of these canals, it was an arid agricultural region with minimal output. Furthermore, the irrigation was dependent on rain due to the lack of nearby natural water sources.

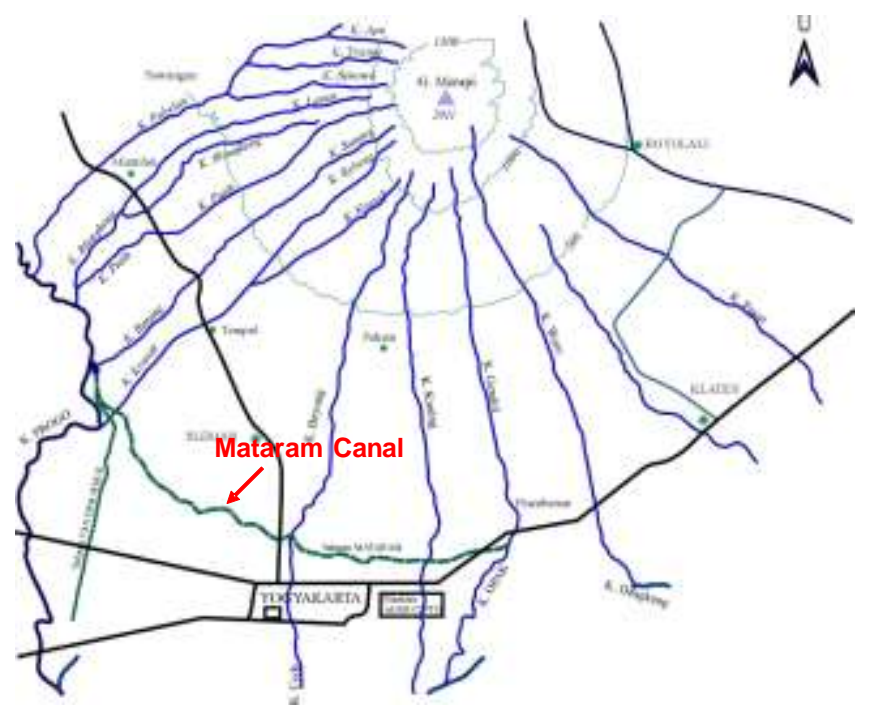

Figure 4. Mataram Canal and river system at Yogyakarta Province

The above analysis, showed the important role or functions of the Mataram Canal in conveying water from the Progo River at the west flange of 
Mt. Merapi into its east flange. Some of these advantages are associated with the ability to provide more water for many purposes including irrigation in the city's municipality. Currently, it is much larger in size with the capability to connect two important rivers. Today, some places along the canal have become tourist destinations, and it is more popular in Yogyakarta due to its architectural history. However, the diversification of water utilization in fishery ponds along the canal and the shift in land utilization from rice field to housings, and government buildings may undermine the function of the canal. In addition to this, the several hydraulics infrastructures such as roads, rivers, and distribution structures are also detrimental to its existence. In extreme cases, the distribution structures are no longer required.

\section{METHODS}

A number of methods such as Strength -Weakness - Opportunity - Threat (SWOT), Analytical Hierarchy Process (AHP), and Quantitative Strategic Planning Matrix (QSPM), are used to assess or evaluate the water infrastructure heritage and its position within the integrated water resources management (IWRM) program. The Strength-Weakness-Opportunity-Threat (SWOT) of Mataram Canal operation and maintenance is established in accordance with the key performance indicators as shown in Table 1. The conceptual framework of the valuation technique comprises of a SWOT method and its position in the IWRM program. The components of Mataram Canal to be examined are grouped into three major components namely
Karangtalun, the hydraulic, and measurement structures. Some key performance indicators (KPI) related to IWRM is water conservation, utilization, destructive power control and the legal aspects. The aforementioned IWRM-related KPI are items related to the performance of its components to function properly.

The items to be considered as part of IWRM include the performance of each component valued from various viewpoints such as water conservation, utilization, destructive control facilities, as well as the community and institution organization involved. In line with the rapid development of population along and nearby canal, potential water quality degradation often takes place due to the inflow of domestic wastewater. Some cases on further development of the operation and maintenance program of the infrastructure components need a careful consideration, irrespective of its maintenance structure, whether left or demolished. The costeffectiveness of the operation and maintenance of Mataram Canal is a dominant factor in evaluating and creating a bias conclusion. Judging from the experience of a number of examples discussed in the previous chapter, and the fact that the real function of water is not merely for food, the results of the evaluation becomes comprehensive and acceptable. Further, a survey along the canal was conducted to identify its condition, function and structure. The collected photographs were then observed in more detail to study the value in term of IWRM and as a heritage. In addition, other findings related to the canal were recorded and discussed in Table 1. 
Table 1. Chart of SWOT Method and its position in the IWRM Program

\begin{tabular}{lll}
\hline & Strength (S) & Weakness (W) \\
\hline & IWRM-related KPI (1) & IWRM-related KPI (1) \\
& IWRM-related KPI (2) & IWRM-related KPI (2) \\
& IWRM-related KPI (3) & IWRM-related KPI (3) \\
& IWRM-related KPI (..) & IWRM-related KPI (..) \\
& IWRM-related KPI (..) & IWRM-related KPI (..) \\
\hline Opportunity (O) & S-O (Strategy) & W-O (Strategy) \\
\hline IWRM-related KPI (1) & & \\
IWRM-related KPI (2) & & \\
IWRM-related KPI (3) & & \\
IWRM-related KPI (..) & & \\
IWRM-related KPI (..) & & \\
\hline Threat (T) & S-T (Strategy) & \\
\hline IWRM-related KPI (1) & & \\
IWRM-related KPI (2) & & \\
IWRM-related KPI (3) & & \\
IWRM-related KPI (..) & & \\
IWRM-related KPI (..) & & \\
\hline
\end{tabular}

\section{RESULTS AND DISCUSSION}

Rao (2017) stated that one of three goals of the preservation of the ancient Indian water infrastructure of Baoli is to revive ancient systems. This is similar to the function of Mataram Canal and its integration to the program of IWRM as shown in Table 2. Several components are selected and examined in qualitative measures. The SWOT analysis shown in Table 2 is related to the necessity of sustaining the Mataram Canal as the water-related infrastructure and their compliances with the management program. The S-O strategy is used to support the remaining agricultural land with water and to improve its value through the production of high value plantations, recreations, industries, education as well as tourism. The opportunities with regard to information technologies have made it easy for operation and maintenance. These information technologies also make it possible to socialize the canal heritage and educate people at lower cost. The $\mathrm{W}$-O strategies keep the canal in a good shape while minimizing its maintenance cost. Furthermore, information technologies play a vital role with the S-T strategies used to reduce the risk of possible natural disaster, while supporting S-O and other legal organizations to create better awareness. Finally, the optimization of the management and its involvement in empowering the related institutions of IWRM are the strategies for W-T section.

Two efforts are proposed as strategies to accommodate the weaknesses and threats of the canal namely the optimization of the watersediment related management and empowerment of the institutions related to sustaining its heritage. Therefore, both government and nongovernment institutions need to underline important goals in sustaining the ancient Mataram Canal by educating people on its historic and architectural relevance. 


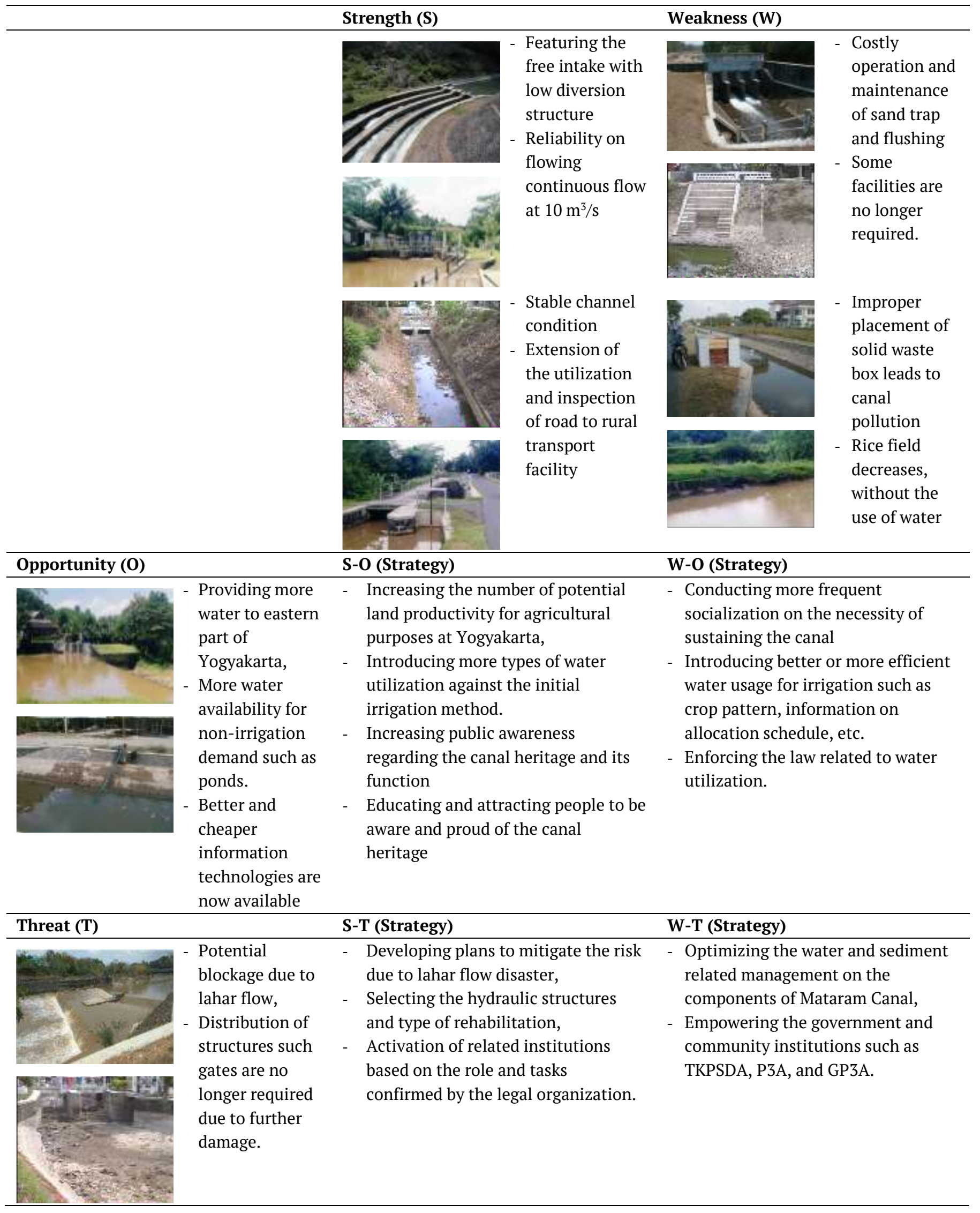




\section{CONCLUSIONS}

Understanding the functional design of the ancient water-related infrastructure requires data and information obtained through limited condition. However, despite the simplicity associated with acquiring these data, it significantly helps in identifying the functional design of the water-related infrastructure. The assessment result of the heritage water-related infrastructure showed that several programs utilize the $\mathrm{S}-\mathrm{O}, \mathrm{W}-\mathrm{O}, \mathrm{S}-\mathrm{T}$, and $\mathrm{W}-\mathrm{T}$ strategies. Among these, the $\mathrm{W}-\mathrm{T}$ is considered the top priority, which includes the revitalization of the infrastructure components and the empowerment of the water-related institutions of TKPSDA. This is followed by the S-T, W-O, and SO. However, further development is needed for the physical activity using the quantitative measure.

\section{DISCLAIMER}

The authors declare no conflict of interest.

\section{ACKNOWLEDGMENTS}

The authors are gratitude to the Tourist Agency of Yogyakarta Province for providing information regarding the history of the ancient history of the Mataram Canal Development. The authors are also grateful to the Serayu Opak River Basin for their assistance.

\section{REFERENCES}

Baolis (Step Wells) of Delhi, 2017. [Online] Available at: https://rangandatta.wordpress.com/20170510/ba olis-step-wells-of-delhi [Accessed 27 September 2019]

Baolis of Mehrauli, 2019. [Online] Available at: https://en.wikipedia.org/wiki/Baolis_of_Mehrauli [Accessed 27 September 2019]

Rao, P.R.N., 2017. Water and Heritage: Rejuvenation of Baoli Precincts, New Delhi: Delhi Urban Art Commission.

Tamai, N., Todo, H., \& Ikemoto, T., 2018. Changes of a Route and an Upstream Well for an Inverted Siphon of Tatsumi Canal in City of Kanazawa. Yogyakarta, $21^{\text {st }}$ IAHR-APD Congress 2018.

Tatsumi Canal, 2019, [Online] Available at: https://en.wikipedia.org/wiki/Tatsumi_Canal [Accessed 27 September 2019]

The Tatsumi Canal (Falls) in Kanazawa, Ishikawa, Japan, 2019, [Online] Available at: https://commons.wikimedia.org/wiki/Category:T atsumi_Canal\#/media/File:Tatsumi_canal_(Falls). jpg, [Accessed 27 September 2019]

Triatmadja. R., Legono, D., Wignyosukarto, B.S., Nurrochmad, F., \& Sunjoto, S., 2018. Van Der Wijck Irrigation Channel, A Success Story and its Implication. Yogyakarta, $21^{\text {st }}$ IAHR-APD Congress 2018.

Vishwanath, S., 2010. Know Your Water Heritage. [Online] Available at: https://www.indiawaterportal.org/news/knowyour-water-heritage-s-vishwanath [Accessed 27 September 2019]. 
[This page is intentionally left blank] 